\title{
Role of Tunable Acid Catalysis in Decomposition of $\alpha$-Hydroxyalkyl Hydroperoxides and Mechanistic Implications for Tropospheric Chemistry
}

\author{
Manoj Kumar, ${ }^{\dagger, \ddagger}$ Daryle H. Busch, ${ }^{\dagger \neq}$ Bala Subramaniam, ${ }^{\ddagger}, \S$ and Ward H. Thompson $*, \dagger, \ddagger$ \\ ${ }^{\dagger}$ Department of Chemistry, University of Kansas, Lawrence, Kansas 66045, United States \\ ${ }^{\ddagger}$ Center for Environmentally Beneficial Catalysis, 1501 Wakarusa Drive, Lawrence, Kansas 66047, United States \\ ${ }^{\S}$ Department of Chemical and Petroleum Engineering, University of Kansas, Lawrence, Kansas 66045, United States
}

Supporting Information

ABSTRACT: Electronic structure calculations have been used to investigate possible gasphase decomposition pathways of $\alpha$-hydroxyalkyl hydroperoxides (HHPs), an important source of tropospheric hydrogen peroxide and carbonyl compounds. The uncatalyzed as well as waterand acid-catalyzed decomposition of multiple HHPs have been examined at the M06-2X/augcc-pVTZ level of theory. The calculations indicate that, compared to an uncatalyzed or watercatalyzed reaction, the free-energy barrier of an acid-catalyzed decomposition leading to an aldehyde or ketone and hydrogen peroxide is dramatically lowered. The calculations also find a direct correlation between the catalytic effect of an acid and the distance separating its hydrogen acceptor and donor sites. Interestingly, the catalytic effect of an acid on the HHP decomposition resulting in the formation of carboxylic acid and water is relatively much smaller. Moreover, since the free-energy barrier of the acid-catalyzed aldehyde- or ketoneforming decomposition is $\sim 25 \%$ lower than that required to break the $\mathrm{O}-\mathrm{OH}$ linkage of the HHP leading to the formation of hydroxyl radical, these results suggest that HHP

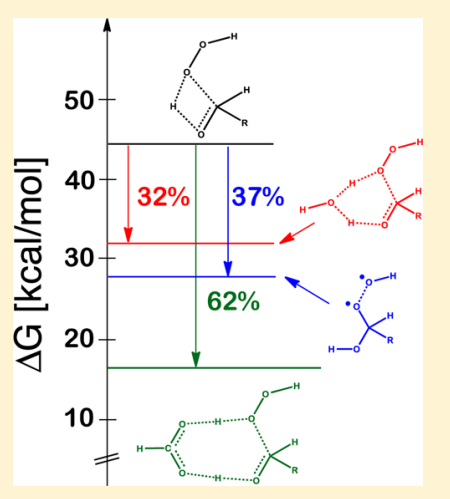
decomposition is likely not an important source of tropospheric hydroxyl radical. Finally, transition state theory estimates indicate that the effective rate constants for the acid-catalyzed aldehyde- or ketone-forming HHP decomposition pathways are 23 orders of magnitude faster than those for the water-catalyzed reaction, indicating that an acid-catalyzed HHP decomposition is kinetically favored as well.

\section{INTRODUCTION}

The gas-phase ozonolysis of olefins constitutes an important degradation mechanism in tropospheric chemistry. It has received considerable recent attention because of its role in the formation of hydroxyl radicals $(\cdot \mathrm{OH})$, hydrogen peroxide $\left(\mathrm{H}_{2} \mathrm{O}_{2}\right)$, organic acids, and aldehydes in the atmosphere. ${ }^{1-11}$ The olefin ozonolysis usually proceeds with the formation of a primary ozonide that subsequently decomposes into the Criegee intermediate (e.g., $\mathrm{R}_{1} \mathrm{R}_{2} \mathrm{COO}$ ) and an aldehyde or a ketone. In the gas-phase, the Criegee intermediate is formed with excess energy and may undergo either unimolecular decomposition or, after collisional stabilization, ${ }^{12-14}$ bimolecular reaction with available reaction partners. ${ }^{15-28}$

A key reaction in atmospheric chemistry is that of water with the stabilized Criegee intermediate. ${ }^{18-23,25-27,29,30}$ It is known that this reaction leads to the formation of hydroxyalkyl hydroperoxide, carboxylic acids, carbonyl compounds, and $\mathrm{H}_{2} \mathrm{O}_{2}$, 4,6,31-33 species with important environmental implications. In particular, $\mathrm{H}_{2} \mathrm{O}_{2}$ is a molecule of broad tropospheric and biological relevance. ${ }^{34}$ Because of its possible role in sulfate formation in clouds and aqueous aerosols, ${ }^{35,36} \mathrm{H}_{2} \mathrm{O}_{2}$ is tightly tied to acid rain and global climate change. ${ }^{37}$ Recently, $\mathrm{H}_{2} \mathrm{O}_{2}$ has also been detected in the extraterrestrial environments of
Mars, ${ }^{38}$ enhancing general interest in a clear and insightful understanding of its mechanism of formation.

Although $\mathrm{H}_{2} \mathrm{O}_{2}$ is thought to be primarily produced in the gas-phase via the photochemical $\mathrm{HO}_{2}$ radical recombination reaction, ${ }^{39-41}$ the reactions of biogenic and anthropogenic alkenes with ozone also constitute an important nonphotochemical source of tropospheric $\mathrm{H}_{2} \mathrm{O}_{2} \cdot{ }^{1-11}$ In particular, the decomposition of $\alpha$-hydroxyalkyl hydroperoxide (HHP), which is produced in the Criegee intermediate reaction with water, $^{30,42}$ serves as the principal mechanism for nonphotochemical $\mathrm{H}_{2} \mathrm{O}_{2}$ formation (Scheme 1). ${ }^{4-6,31,32}$ The decomposition of HHPs to yield carbonyl compounds or carboxylic acids also has significant industrial promise. ${ }^{43}$ Further, there have been reports ${ }^{7,23}$ suggesting that HHP decomposition can provide an additional source of atmospheric $\cdot \mathrm{OH}$, although this topic remains controversial. $6,8,19-22,44,45$

Theoretical calculations indicate that HHP decomposition is kinetically slow because of its extremely high activation barrier of $\sim 50.0 \mathrm{kcal} / \mathrm{mol}^{19-23}$ However, the presence of a single water molecule promotes the decomposition by reducing the

Received: May 23, 2014

Revised: September 17, 2014

Published: September 18, 2014 
Scheme 1. General Carboxylic Acid- (left) and Aldehyde-Forming (right) Decomposition Pathways of $\alpha$-Hydroxyalkyl Hydroperoxides

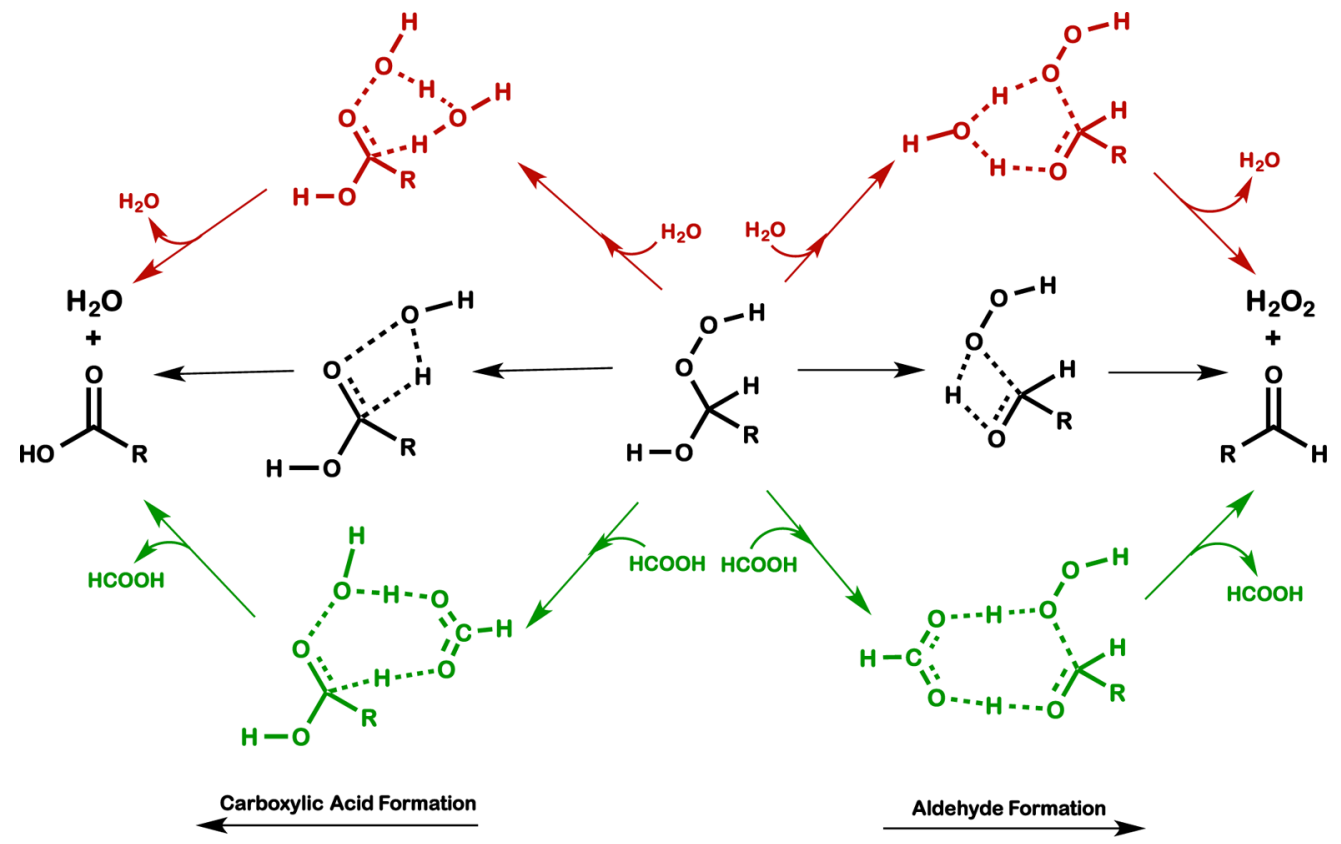

free-energy barrier by $\sim 14.0 \mathrm{kcal} / \mathrm{mol} .^{19-22}$ Although the mechanism of HHP decomposition has been extensively studied over the past few years, ${ }^{6,8,19-23,44-46}$ key mechanistic questions remain: Do molecules other than water catalyze HHP decomposition in the troposphere? Is the HHP decomposition a source of $\cdot \mathrm{OH}$ in the atmosphere?

In this article, we explore the catalysis of HHP decomposition by an organic or inorganic acid including the reaction pathways for different products such as $\mathrm{H}_{2} \mathrm{O}_{2}$ and $\cdot \mathrm{OH}$. Organic acids are present in parts per billion concentrations in the troposphere. ${ }^{47,48}$ While their catalytic ability to promote unimolecular hydrogen atom $(\mathrm{H}$ atom) transfer reactions has increasingly been recognized, ${ }^{49-53}$ the ability of organic acids to catalyze HHP decomposition has not been explored.

\section{COMPUTATIONAL METHODS}

We have investigated the uncatalyzed, water-catalyzed, and acid-catalyzed decomposition pathways (both aldehyde- and carboxylic acid-forming) for a variety of HHPs. Specifically, we considered the simplest HHPs, hydroxymethyl hydroperoxide $\left(\mathrm{HHP}_{\mathrm{C} 1}\right)$ and hydroxyethyl hydroperoxide $\left(\mathrm{HHP}_{\mathrm{C} 2}\right)$, as well as those resulting from the ozonolysis of biogenic isoprene $\left(\mathrm{HHP}_{\text {isoprene1 }}\right.$ and $\left.\mathrm{HHP}_{\text {isoprene2 }}\right)$; see Scheme 2. Isoprene is one of the most abundant hydrocarbons emitted in the biosphere, ${ }^{54,55}$ and its ozonolysis reaction is not only an important chemical sink in the atmosphere but also relevant for aerosol formation. Since an HHP can exist in two conformations differing in the relative spatial orientation of the perhydroxy hydrogen and the hydroxyl hydrogen (Scheme 2), we have considered both conformations for all the HHP investigated here. Our calculations indicate that the trans-HHP conformation, in which the perhydroxy hydrogen and hydroxyl hydrogen are rotated away from each other, is more stable than the cis conformation and leads to lower energy pathways.

Both density functional theory (DFT) and ab initio calculations have been carried out to provide a detailed mechanistic insight into the gas-phase decomposition of HHPs.
Scheme 2. $\alpha$-Hydroxyalkyl Hydroperoxides Studied in This Work<smiles>OOCCOO</smiles><smiles>C=CC(C)(O)OO</smiles><smiles>C=CC(C)(O)OO</smiles>

trans

cis

$\mathrm{HHP}_{\text {isoprene1 }}$<smiles>CC(OO)OO</smiles><smiles>C=C(C)C(O)OO</smiles>

trans

$\mathrm{HHP}_{\text {isoprene2 }}$

Methods in the latter category include coupled cluster with single and double excitations (CCSD), CCSD (T), QCISD, and local pair natural orbital coupled electron pair approximation version 1 (LPNO-CEPA/1) ${ }^{56}$ calculations. The LPNO-CEPA/ 1 method is gaining recognition because of its accuracy and computational efficiency. 5

As a first step, we performed a detailed DFT investigation of the gas-phase decomposition of a single $\mathrm{HHP}_{\mathrm{C} 1}$ molecule. All the structures were fully optimized at the M06-2X/aug-ccpVTZ level, and frequencies were calculated to ensure that the optimized structures are either true minima or first-order saddle points and to estimate the thermodynamic quantities. Using the M06-2X-optimized geometries, the barrier heights were also estimated using the single-point calculations $\mathrm{Y} /$ aug-cc-pVTZ// M06-2X/aug-cc-pVTZ (Y = DFT, CCSD, CCSD(T), QCISD, or LPNO-CEPA/1) as well as full geometry optimizations with a variety of DFT functionals that include B3LYP, BP86, 
O3LYP, MPW1PW91, MPW1K, M06-L, PBE, TPSSh, and B97-D. Our results (Tables S1 and S2, Supporting Information) indicate that the M06-2X/aug-cc-pVTZ-estimated electronic-energy barrier of $48.6 \mathrm{kcal} / \mathrm{mol}$ for the uncatalyzed formaldehyde-forming decomposition of $\mathrm{HHP}_{\mathrm{C} 1}$ is only 1.1 $\mathrm{kcal} / \mathrm{mol}$ higher than the $\mathrm{CCSD}(\mathrm{T}) /$ aug-cc-pVTZ//M06-2X/ aug-cc-pVTZ-calculated value of $47.5 \mathrm{kcal} / \mathrm{mol}$. Moreover, it is in very good agreement with the recently reported values of 48.1-52.0 $\mathrm{kcal} / \mathrm{mol}$ based on CCSD(T) or CBS-QB3 singlepoint energies. ${ }^{19-23}$ This level of theory, has also been previously found to provide a fairly accurate description of atmospherically important $\mathrm{H}$ atom transfer processes such as carbonic acid decomposition, isomerization of methoxy radical, and tautomerization of vinyl alcohol. ${ }^{49}$ Because of this chemical accuracy and its computational efficiency, we selected the M062X/aug-cc-pVTZ method for studying the HHP decomposition chemistry.

To understand the catalytic effect of an acid on the gas-phase decomposition of $\mathrm{HHP}$, we considered water, $\mathrm{HCOOH}$, and inorganic acids. All the calculated reaction profiles are reported in terms of Gibbs free energies at $298.15 \mathrm{~K}$ and 1 atm to account for the entropic effects associated with the complexation of the catalyst. In order to establish a relationship between the catalytic activity of an acid and its acid dissociation constant $\left(\mathrm{p} K_{\mathrm{a}}\right)$, the experimentally determined $\mathrm{p} K_{\mathrm{a}} \mathrm{s}$ were used. ${ }^{58}$ The decomposition of the larger HHPs $\left(\mathrm{HHP}_{\mathrm{C} 2}, \mathrm{HHP}_{\text {isoprenel }}\right.$, and $\mathrm{HHP}_{\text {isoprene2 }}$ ) was only studied in the presence of $\mathrm{H}_{2} \mathrm{O}$ and $\mathrm{HCOOH}$ catalysts. To examine the possible tropospheric impact of the acid catalysis on the HHP decompositions investigated in this study, the rate constants for the uncatalyzed and catalyzed reactions were estimated using transition state theory. The NWChem ${ }^{59}$ software was used for the DFT, $\operatorname{CCSD}, \operatorname{CCSD}(\mathrm{T})$, and QCISD calculations, while the LPNO$\mathrm{CEPA} / 1$ calculations were carried out with the $\mathrm{ORCA}^{60}$ program.

\section{RESULTS AND DISCUSSION}

3.1. Unimolecular $\mathrm{HHP}_{\mathrm{C} 1}$ Decomposition. The unimolecular decomposition of $\mathrm{HHP}_{\mathrm{C} 1}$ that produces formaldehyde and $\mathrm{H}_{2} \mathrm{O}_{2}$ is a high barrier $1,3-\mathrm{H}$ atom transfer reaction, which occurs between the hydroxyl and perhydroxy functionalities via a four-membered transition state (Figure 1). At the M06-2X/ aug-cc-pVTZ level of theory, the zero-point-corrected $\Delta E^{\ddagger}$ for the decomposition of a trans- $\mathrm{HHP}_{\mathrm{C} 1}$ molecule is $44.6 \mathrm{kcal} / \mathrm{mol}$, $\Delta G^{\ddagger}$ is $44.7 \mathrm{kcal} / \mathrm{mol}$, and the reaction is endergonic by 5.2 $\mathrm{kcal} / \mathrm{mol}$ (Figure 1 and Table 1 ). For the similar uncatalyzed decomposition of a cis-HHP $\mathrm{Cl}_{\mathrm{C}}$ molecule, the $\Delta E^{\ddagger}$ and $\Delta G^{\ddagger}$ are 46.3 and $46.2 \mathrm{kcal} / \mathrm{mol}$, respectively (Table S3, Supporting Information).

The unimolecular decomposition of $\mathrm{HHP}_{\mathrm{C} 1}$ can follow an alternate mechanistic route that involves a $1,2-\mathrm{H}$ atom transfer between the $-\mathrm{CH}$ group and the hydroperoxy oxygen and leads to the formation of a formic acid and a water molecule (Figure 1). Previous calculations ${ }^{19-23}$ and the current results predict that this alternate pathway involves a much larger barrier $\left(\Delta G^{\ddagger}=57.9 \mathrm{kcal} / \mathrm{mol}\right.$ for trans- $\mathrm{HHP}_{\mathrm{C} 1} ; 58.6 \mathrm{kcal} / \mathrm{mol}$ for cis- $\mathrm{HHP}_{\mathrm{C} 1}$, at the M06-2X level) due to the cleavage of the strong $\mathrm{C}-\mathrm{H}$ bond and is thus expected to be a minor decomposition channel (Figure 1 and Table 2). Despite being a high barrier process, this decomposition channel is strongly exergonic with $\Delta G_{\mathrm{rxn}}=-81.9 \mathrm{kcal} / \mathrm{mol}\left(\right.$ trans $\left.-\mathrm{HHP}_{\mathrm{C} 1}\right)$ and $-81.2 \mathrm{kcal} / \mathrm{mol}\left(\right.$ cis- $\left.\mathrm{HHP}_{\mathrm{C} 1}\right)$, in contrast to the endergonic formaldehyde-forming reaction.

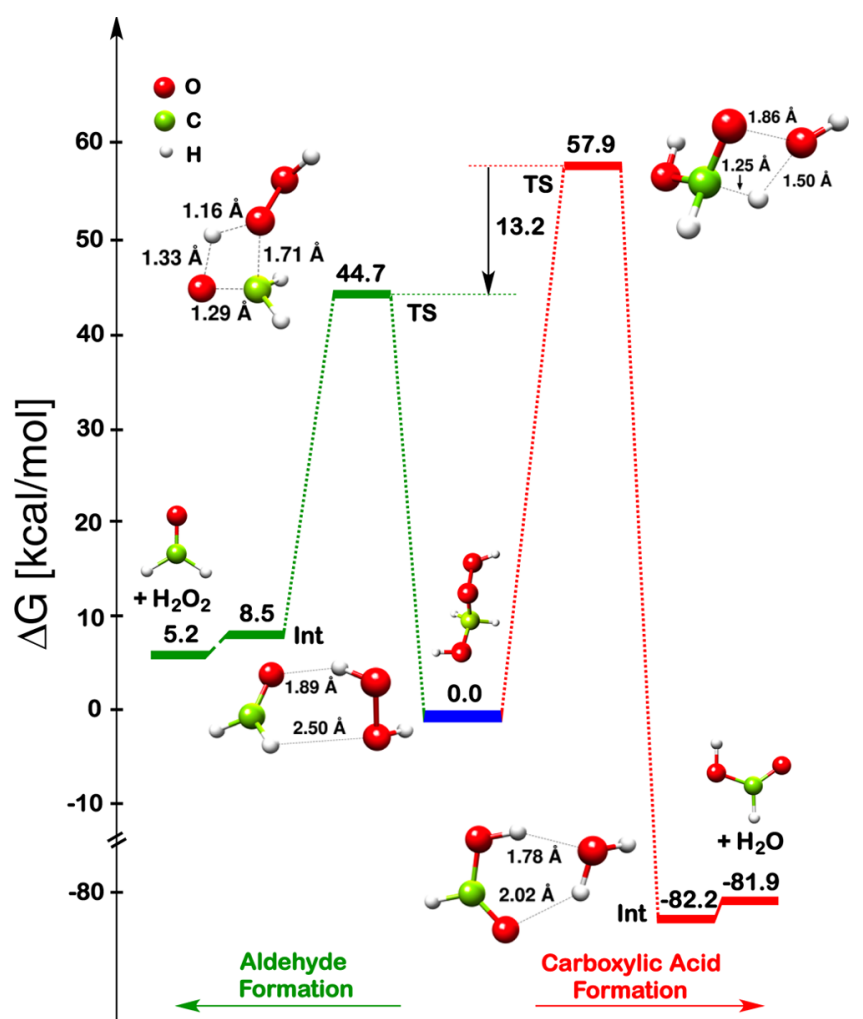

Figure 1. M06-2X/aug-cc-pVTZ-calculated free-energy profile (298.15 $\mathrm{K}, 1 \mathrm{~atm}$ ) for the uncatalyzed formaldehyde-(left; green lines) and formic acid-forming (right; red lines) gas-phase decomposition of a trans- $\mathrm{HHP}_{\mathrm{C} 1}$ molecule.

3.2. Water-Catalyzed $\mathrm{HHP}_{\mathrm{C} 1}$ Decomposition. Since $\mathrm{H}_{2} \mathrm{O}$ is the dominant trace component in the troposphere, it is important to examine its influence on the decomposition reaction. Although Anglada et al. have previously studied the role of $\mathrm{H}_{2} \mathrm{O}$ catalysis on the gas-phase $\mathrm{HHP}_{\mathrm{C} 1}$ decomposition using electronic structure methods, ${ }^{19}$ we have recalculated the potential energy surface including a single $\mathrm{H}_{2} \mathrm{O}$ molecule to facilitate the comparison between acid-assisted and $\mathrm{H}_{2} \mathrm{O}$ assisted decomposition on an equal theoretical footing. Our calculated mechanism of water catalysis is the same as the previously proposed one, ${ }^{19}$ i.e., the reaction occurs in a stepwise manner, involving the formation of a prereaction complex, $\mathrm{HHP}_{\mathrm{Cl}} \cdots \mathrm{H}_{2} \mathrm{O}\left(\right.$ Int $\left._{1}\right)$, transition state (TS), and postreaction complex $\left(\mathbf{I n t}_{2}\right)$, respectively (Figures 2 and S1, Supporting Information). The zero-point-corrected $\Delta E^{\ddagger}$ for the $\mathrm{H}_{2} \mathrm{O}$ catalyzed decomposition of a trans- $\mathrm{HHP}_{\mathrm{C} 1}$ molecule is 21.0 $\mathrm{kcal} / \mathrm{mol}$, which is reduced by more than half compared to the uncatalyzed reaction. However, it is important to include entropic effects in the calculations, which disfavor both the prereaction complex, $\mathbf{I n t}_{\mathbf{1}}$, and transition state (Table 1 ). The calculated $\Delta G^{\ddagger}$ for the $\mathrm{H}_{2} \mathrm{O}$-assisted decomposition is 30.6 $\mathrm{kcal} / \mathrm{mol}$, which is only $14.1 \mathrm{kcal} / \mathrm{mol}$ lower than the uncatalyzed reaction. This is consistent with the previous study by Anglada et al., who predicted a $\Delta G^{\ddagger}$ lowering of 14.0 $\mathrm{kcal} / \mathrm{mol}$ for the $\mathrm{H}_{2} \mathrm{O}$-assisted decomposition. ${ }^{19}$ The calculations also indicate that water has similar catalytic effect on the cis-HHP ${ }_{\mathrm{CI}}$ decomposition (Figure S1 and Table S3, Supporting Information). The catalytic effect of a water molecule in the formaldehyde-forming reaction is due to its ability to act as a shuttle for a $1,3-\mathrm{H}$ atom transfer, with the water oxygen abstracting the $\mathrm{H}$ atom from the $\alpha$-hydroxy site of $\mathrm{HHP}_{\mathrm{C} 1}$ and 
Table 1. M06-2X/aug-cc-pVTZ-Calculated Energies $(298.15 \mathrm{~K}, 1 \mathrm{~atm}, \mathrm{kcal} / \mathrm{mol})$ of Various Species Involved in the Uncatalyzed and Catalyzed Aldehyde- or Ketone-Forming Gas-Phase Decomposition of trans-HHPs Studied in the Present Work ${ }^{a}$

\begin{tabular}{|c|c|c|c|c|c|c|c|c|c|}
\hline \multirow[b]{2}{*}{ substrate } & \multirow[b]{2}{*}{ catalyst } & \multicolumn{2}{|c|}{ Int $_{1}$} & \multicolumn{2}{|c|}{ TS } & \multicolumn{2}{|c|}{ Int $_{2}$} & \multicolumn{2}{|c|}{$\mathrm{P}$} \\
\hline & & $\Delta E$ & $\Delta G$ & $\Delta E$ & $\Delta G$ & $\Delta E$ & $\Delta G$ & $\Delta E$ & $\Delta G$ \\
\hline \multirow[t]{9}{*}{$\mathrm{HHP}_{\mathrm{Cl}}$} & none & & & 44.6 & 44.7 & 10.1 & 8.5 & 15.6 & 5.2 \\
\hline & $\mathrm{H}_{2} \mathrm{O}$ & -9.1 & -0.6 & 21.0 & 30.6 & 3.9 & 10.8 & 15.6 & 5.2 \\
\hline & $\mathrm{HCOOH}$ & -12.2 & -1.6 & 5.4 & 16.9 & -0.8 & 8.3 & 15.6 & 5.2 \\
\hline & $\mathrm{HNO}_{2}$ & -8.1 & 2.2 & 13.4 & 24.7 & 3.7 & 12.2 & 15.6 & 5.2 \\
\hline & $\mathrm{HNO}_{3}$ & -11.5 & -0.7 & 6.8 & 18.0 & 0.0 & 9.7 & 15.6 & 5.2 \\
\hline & $\mathrm{H}_{2} \mathrm{SO}_{3}$ & -16.7 & -4.9 & 1.3 & 13.1 & -2.9 & 7.1 & 15.6 & 5.2 \\
\hline & $\mathrm{H}_{2} \mathrm{SO}_{4}$ & -14.5 & -3.7 & -0.2 & 10.9 & -3.1 & 6.7 & 15.6 & 5.2 \\
\hline & $\mathrm{HClO}_{2}$ & -15.0 & -4.0 & 0.6 & 12.4 & -4.6 & 5.5 & 15.6 & 5.2 \\
\hline & $\mathrm{H}_{3} \mathrm{AsO}_{2}$ & -16.6 & -5.4 & -1.6 & 10.0 & -7.1 & 3.5 & 15.6 & 5.2 \\
\hline \multirow[t]{3}{*}{$\mathrm{HHP}_{\mathrm{C} 2}$} & none & & & 42.5 & 42.2 & 6.7 & 4.4 & 13.1 & 1.7 \\
\hline & $\mathrm{H}_{2} \mathrm{O}$ & -7.0 & 1.5 & 19.0 & 28.5 & -0.2 & 6.9 & 13.1 & 1.7 \\
\hline & $\mathrm{HCOOH}$ & -12.3 & -1.6 & 2.8 & 14.3 & -5.9 & 3.1 & 13.1 & 1.7 \\
\hline \multirow[t]{3}{*}{$\mathrm{HHP}_{\text {isoprenel }}$} & none & & & 38.7 & 38.4 & 1.2 & -1.1 & 8.6 & -3.4 \\
\hline & $\mathrm{H}_{2} \mathrm{O}$ & -7.3 & 1.5 & 17.0 & 26.5 & -5.1 & 0.7 & 8.6 & -3.4 \\
\hline & $\mathrm{HCOOH}$ & -12.7 & -1.9 & 0.4 & 12.0 & -10.5 & -2.0 & 8.6 & -3.4 \\
\hline \multirow[t]{3}{*}{$\mathrm{HHP}_{\text {isoprene2 }}$} & none & & & 41.0 & 40.6 & 3.4 & 1.0 & 10.0 & -1.5 \\
\hline & $\mathrm{H}_{2} \mathrm{O}$ & -7.2 & 1.5 & 17.3 & 26.9 & -3.3 & 2.8 & 10.0 & -1.5 \\
\hline & $\mathrm{HCOOH}$ & -12.6 & -2.2 & 1.3 & 12.7 & -8.1 & -0.2 & 10.0 & -1.5 \\
\hline
\end{tabular}

${ }^{a}$ All energies are relative to the separated HHP and catalyst. For the uncatalyzed reactions, Int $_{2}$ refers to Int. See Table S3, Supporting Information, for the data corresponding to the decomposition of cis-HHPs.

Table 2. M06-2X/aug-cc-pVTZ-Calculated Energies (298.15 K, $1 \mathrm{~atm}, \mathrm{kcal} / \mathrm{mol}$ ) of Various Species Involved in the Uncatalyzed and Acid-Catalyzed Formic Acid- and Acetic Acid-Forming Gas-Phase Decomposition of HHP $\mathrm{C}_{\mathrm{C} 1}$ and $\mathrm{HHP}_{\mathrm{C} 2}$; All Energies Are Relative to the Separated HHP and Catalyst

\begin{tabular}{|c|c|c|c|c|c|c|c|c|c|c|}
\hline \multirow[b]{2}{*}{ substrate } & \multirow[b]{2}{*}{ conformer } & \multirow[b]{2}{*}{ catalyst } & \multicolumn{2}{|c|}{ Int $_{1}$} & \multicolumn{2}{|c|}{ TS } & \multicolumn{2}{|c|}{ Int $_{2}$} & \multicolumn{2}{|c|}{$\mathrm{P}$} \\
\hline & & & $\Delta E$ & $\Delta G$ & $\Delta E$ & $\Delta G$ & $\Delta E$ & $\Delta G$ & $\Delta E$ & $\Delta G$ \\
\hline \multirow[t]{6}{*}{$\mathrm{HHP}_{\mathrm{Cl}}$} & cis & none & & & 58.6 & 58.6 & -80.9 & -81.5 & -72.1 & -81.2 \\
\hline & & $\mathrm{H}_{2} \mathrm{O}$ & -7.0 & 2.1 & 42.1 & 51.7 & -90.3 & -82.4 & -72.1 & -81.2 \\
\hline & & $\mathrm{HCOOH}$ & -6.7 & 3.3 & 36.1 & 47.2 & -88.3 & -79.2 & -72.1 & -81.2 \\
\hline & trans & none & & & 58.0 & 57.9 & -81.5 & -82.2 & -72.8 & -81.9 \\
\hline & & $\mathrm{H}_{2} \mathrm{O}$ & -6.3 & 2.0 & 40.4 & 49.8 & -90.9 & -83.1 & -72.8 & -81.9 \\
\hline & & $\mathrm{HCOOH}$ & -7.3 & 2.6 & 34.5 & 45.8 & -88.9 & -79.9 & -72.8 & -81.9 \\
\hline \multirow[t]{6}{*}{$\mathrm{HHP}_{\mathrm{C} 2}$} & cis & none & & & 59.8 & 59.6 & -83.3 & -84.8 & -74.3 & -84.0 \\
\hline & & $\mathrm{H}_{2} \mathrm{O}$ & -7.1 & 1.8 & 43.5 & 52.8 & -92.4 & -85.3 & -74.3 & -84.0 \\
\hline & & $\mathrm{HCOOH}$ & -7.1 & 3.1 & 38.5 & 49.5 & -90.6 & -82.9 & -74.3 & -84.0 \\
\hline & trans & none & & & 59.5 & 59.2 & -83.6 & -85.2 & -74.6 & -84.4 \\
\hline & & $\mathrm{H}_{2} \mathrm{O}$ & -5.3 & 2.8 & 43.2 & 52.4 & -92.8 & -85.8 & -74.6 & -84.4 \\
\hline & & $\mathrm{HCOOH}$ & -7.5 & 2.7 & 37.2 & 48.3 & -91.0 & -83.3 & -74.6 & -84.4 \\
\hline
\end{tabular}

the hydroperoxy functionality of $\mathrm{HHP}_{\mathrm{C} 1}$ simultaneously accepting an $\mathrm{H}$ atom from $\mathrm{H}_{2} \mathrm{O}$.

We have also calculated the catalytic effect of a water molecule on the alternate $\mathrm{HHP}_{\mathrm{C} 1}$ decomposition pathway that leads to the formation of $\mathrm{HCOOH}$ and $\mathrm{H}_{2} \mathrm{O}$ (Figures 3 and S2, Supporting Information, and Table 2). The calculated $\Delta G^{\ddagger}$ for the $\mathrm{H}_{2} \mathrm{O}$-catalyzed decomposition of a trans- $\mathrm{HHP}_{\mathrm{Cl}}$ molecule is $49.8 \mathrm{kcal} / \mathrm{mol}$, which is only $8.1 \mathrm{kcal} / \mathrm{mol}$ lower than the uncatalyzed reaction. Moreover, the binding free energy of Int $_{1}$ is $2.7 \mathrm{kcal} / \mathrm{mol}$ less than that of the Int $_{1}$ involved in the formaldehyde-forming decomposition. The cleavage of two strong bonds $(\mathrm{O}-\mathrm{OH}$ and $\mathrm{C}-\mathrm{H})$ accounts for the relatively smaller catalytic effect of $\mathrm{H}_{2} \mathrm{O}$ on this decomposition reaction.

3.3. Formic Acid-Catalyzed $\mathrm{HHP}_{\mathrm{C} 1}$ Decomposition. For $\mathrm{HCOOH}$-catalyzed decomposition of $\mathrm{HHP}_{\mathrm{C} 1}$, the general mechanism of catalysis is similar to that of the $\mathrm{H}_{2} \mathrm{O}$-catalyzed reaction, but the catalytic effect is dramatically higher. The calculated $\Delta G^{\ddagger}$ for the $\mathrm{HCOOH}$-catalyzed decomposition of a trans- $\mathrm{HHP}_{\mathrm{C} 1}$ molecule is only $16.9,27.8$, and $13.7 \mathrm{kcal} / \mathrm{mol}$ lower than for the uncatalyzed and $\mathrm{H}_{2} \mathrm{O}$-catalyzed reactions, respectively (Table 1 and Figure 2). A similar catalytic effect is observed for the $\mathrm{HCOOH}$-catalyzed cis- $\mathrm{HHP}_{\mathrm{C} 1}$ decomposition for which $\Delta G^{\ddagger}=18.4 \mathrm{kcal} / \mathrm{mol}$; this is slightly higher than that for the $\mathrm{HCOOH}$-catalyzed trans- $\mathrm{HHP}_{\mathrm{C} 1}$ decomposition and is 27.8 and $13.7 \mathrm{kcal} / \mathrm{mol}$ lower than the corresponding uncatalyzed and $\mathrm{H}_{2} \mathrm{O}$-catalyzed reactions, respectively (Table S3 and Figure S1, Supporting Information). The greater catalytic effect of $\mathrm{HCOOH}$ is due to the presence of oxygen functionalities that provide two separate sites for conducting an $\mathrm{H}$ atom exchange reaction, i.e., the carbonyl oxygen acts as an acceptor for the $\mathrm{H}$ atom from the $\alpha$-hydroxyl group of $\mathrm{HHP}_{\mathrm{C} 1}$, while the hydroxyl oxygen donates the acidic $\mathrm{H}$ atom to the hydroperoxy oxygen of $\mathrm{HHP}_{\mathrm{Cl}}$. Because of the separate donor and acceptor sites, $\mathrm{HCOOH}$ forms a substantially tighter twopoint hydrogen bonding interaction with $\mathrm{HHP}_{\mathrm{C} 1}$ and results in a strongly bound prereaction complex, Int ${ }_{1}$; the calculated 


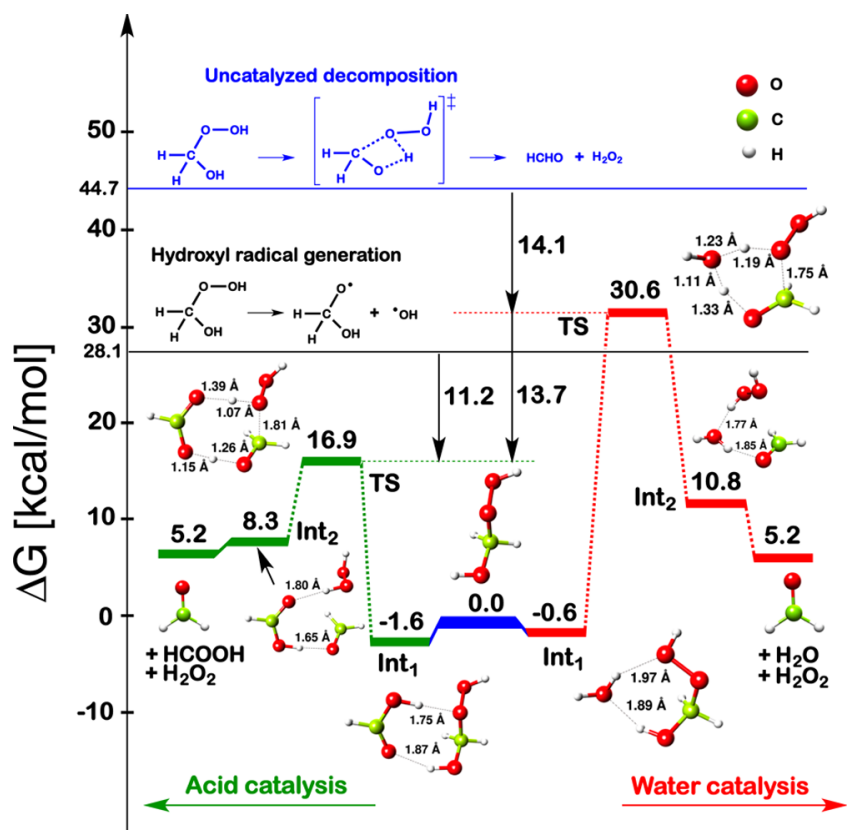

Figure 2. M06-2X/aug-cc-pVTZ-calculated free-energy profile (298.15 $\mathrm{K}, 1 \mathrm{~atm}$ ) of the formic acid- (left; green lines) and water-catalyzed (right; red lines) formaldehyde-forming gas-phase decomposition of a trans- $\mathrm{HHP}_{\mathrm{C} 1}$ molecule. All energies are relative to the separated HHP and catalyst. The horizontal blue and black lines refer to the freeenergy barrier for the uncatalyzed reaction and the reaction free energy of the hydroxyl radical-generating pathway, respectively. See Figure S1, Supporting Information for the free-energy profile of the formic acidand water-catalyzed formaldehyde-forming gas-phase decomposition of a cis-HHP ${ }_{\mathrm{C} 1}$ molecule.

binding free energy of $\operatorname{Int}_{1}(-1.6 \mathrm{kcal} / \mathrm{mol})$ is almost three times higher than that for the $\mathrm{H}_{2} \mathrm{O}$-catalyzed reaction $(-0.6$ $\mathrm{kcal} / \mathrm{mol}$ ). Moreover, the separate donor and acceptor sites in $\mathrm{HCOOH}$ allow the $\mathrm{HCOOH}$-catalyzed reaction to proceed through an eight-membered transition state that is less strained than the six-membered transition state of the water-catalyzed reaction. This leads to a drastic lowering of the free-energy barrier, by $62 \%$ and $45 \%$ for the rate-limiting step of the $\mathrm{HCOOH}$-catalyzed trans- $\mathrm{HHP}_{\mathrm{Cl}}$ decomposition relative to the uncatalyzed and $\mathrm{H}_{2} \mathrm{O}$-catalyzed decomposition, respectively. The postreaction complex, $\mathbf{I n t}_{2}$, involved in the $\mathrm{HCOOH}$ catalyzed decomposition is better stabilized (by $2.5 \mathrm{kcal} / \mathrm{mol}$ ) than that in the $\mathrm{H}_{2} \mathrm{O}$-catalyzed reaction due to stronger hydrogen bonding between $\mathrm{HCOOH}$ and formaldehyde.

In the formic acid-forming decomposition pathway of trans$\mathrm{HHP}_{\mathrm{C} 1}$, the formation of $\operatorname{Int}_{1}(\Delta G=2.6 \mathrm{kcal} / \mathrm{mol})$ is $4.2 \mathrm{kcal} /$ mol less favorable than in the formaldehyde-forming pathway because the $-\mathrm{CH}$ moiety, rather than $-\mathrm{OH}$, interacts with $\mathrm{HCOOH}$. Moreover, the $\Delta G^{\ddagger}$ for the $\mathrm{HCOOH}$-catalyzed reaction is $45.8 \mathrm{kcal} / \mathrm{mol}$, which is only $12.1 \mathrm{kcal} / \mathrm{mol}$ lower than the uncatalyzed version (Figure 3 and Table 2). The calculated $\Delta G^{\dagger}$ of $47.2 \mathrm{kcal} / \mathrm{mol}$ for the HCOOH-catalyzed cis$\mathrm{HHP}_{\mathrm{C} 1}$ decomposition is $11.4 \mathrm{kcal} / \mathrm{mol}$ lower than the uncatalyzed reaction (Figure S2, Supporting Information, and Table 2).

3.4. Key Determinants of Acid Catalysis. Because other acids, in addition to $\mathrm{HCOOH}$, are present in significant concentration in the troposphere and have the required functionality to catalyze an $\mathrm{H}$ atom transfer reaction, ${ }^{50}$ it is important to evaluate their catalytic impact on HHP

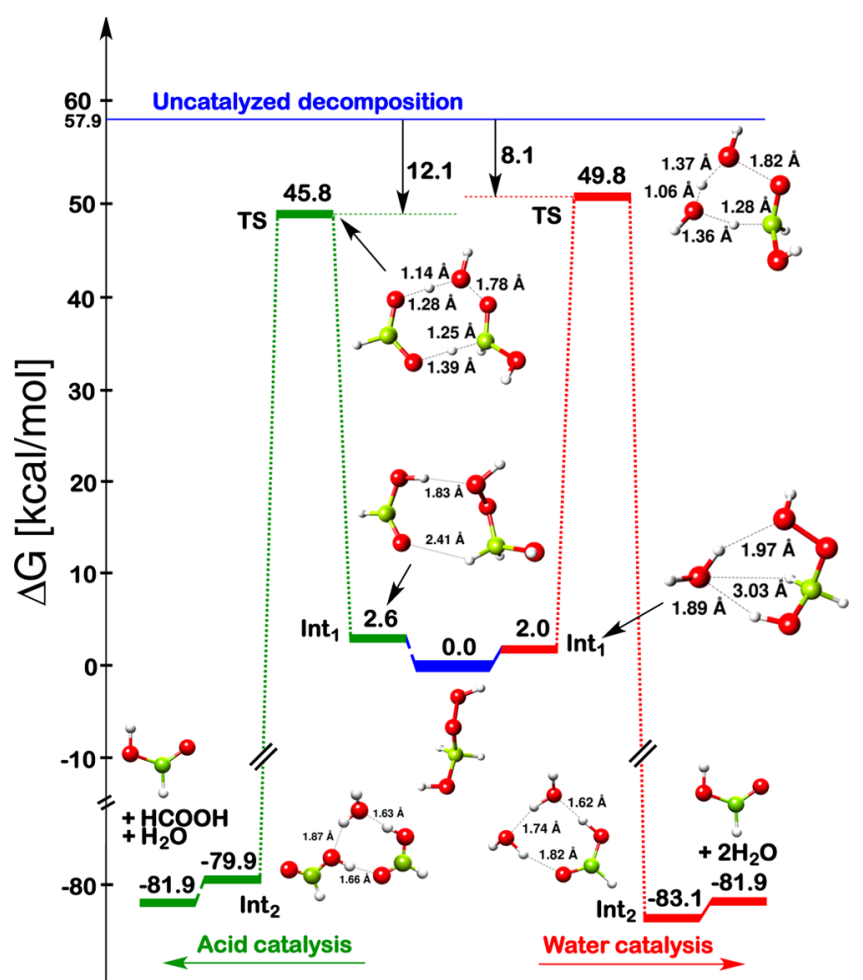

Figure 3. M06-2X/aug-cc-pVTZ-calculated free-energy profile (298.15 $\mathrm{K}, 1 \mathrm{~atm}$ ) for the formic acid- (left; green lines) and water-catalyzed (right; red lines) formic acid-forming gas-phase decomposition of a trans- $\mathrm{HHP}_{\mathrm{Cl}}$ molecule. All energies are relative to the separated HHP and catalyst. The horizontal blue line refers to the free-energy barrier for the uncatalyzed reaction.

decomposition as well. In addition, we recently showed that all organic acids do not necessarily exert a similar catalytic effect on a given $\mathrm{H}$ atom transfer reaction. ${ }^{49}$ Thus, as the next step, we studied the $\mathrm{HHP}_{\mathrm{C} 1}$ decomposition in the presence of various acids to gain insight into the reactivity principles of an acid-catalyzed $\mathrm{H}$ atom transfer reaction.

The results indicate a correlation between the effectiveness of an acid to promote $\mathrm{HHP}_{\mathrm{C} 1}$ decomposition and the distance, $d$, between the acceptor and donor sites of an acid (Figures 4 and S3, Supporting Information; Tables 1 and S3, Supporting Information). Acids with larger $d$ values form expanded cyclic transition states that sterically favor the reaction. Thus, arsinic acid, with $d=2.84 \AA$, is the most potent, while $\mathrm{H}_{2} \mathrm{O}$ with $d=$ $1.63 \AA$ is the least effective catalyst for $\mathrm{HHP}_{\mathrm{C} 1}$ decomposition. Since $\mathrm{H}_{2} \mathrm{O}$ has single oxygen functionality, $d$ in the $\mathrm{H}_{2} \mathrm{O}$ catalyzed reaction is assumed to be the distance between its two hydrogens. Our viewpoint is also supported by recent studies, ${ }^{50,61}$ in which sulfuric acid or sulfonic acid with larger $d(\sim 2.46 \AA)$ was found to be more efficient than a carboxylic acid with smaller $d(\sim 2.24 \AA)$ in catalyzing $\mathrm{H}$ atom transfer.

Note that if the acid $\mathrm{p} K_{\mathrm{a}}$ were the dominant factor, nitrous acid $\left(\mathrm{p} K_{\mathrm{a}}=2.1\right)$ would be a better catalyst than $\mathrm{HCOOH}\left(\mathrm{p} K_{\mathrm{a}}\right.$ $=3.7$ ), which is not the case. For inorganic acids with a constant $d$, the catalytic activity noticeably improves with the number of oxygens or decreasing $\mathrm{p} K_{\mathrm{a}}$ (Tables 1 and S3, Supporting Information). For example, nitric acid and sulfuric acid are better decomposition catalysts than nitrous acid and sulfurous acid, respectively. The analysis of calculated Mulliken atomic charges indicates that the presence of an additional oxygen atom increases the nucleophilicity of the $\mathrm{H}$ atom 

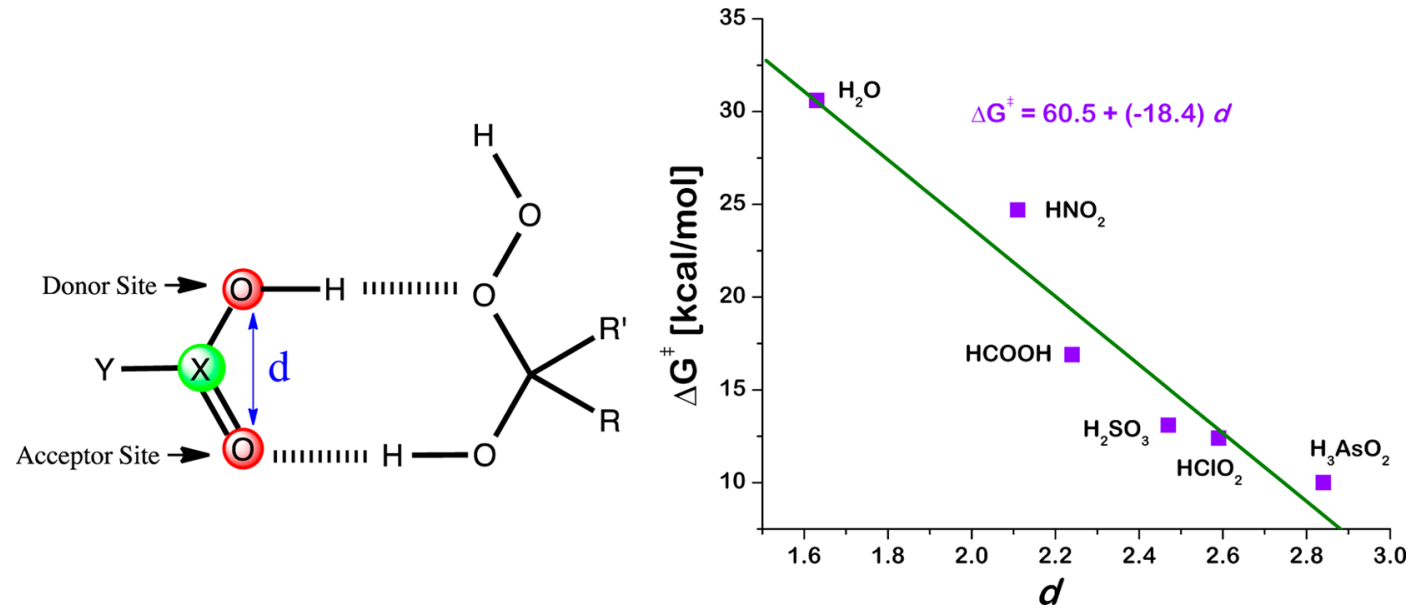

Figure 4. General transition state structure for an acid-catalyzed HHP decomposition (left), and M06-2X/aug-cc-pVTZ-calculated reaction freeenergy barriers in the acid-catalyzed formaldehyde-forming $\mathrm{HHP}_{\mathrm{C} 1}$ decomposition versus $d$, the $\mathrm{O}-\mathrm{O}$ separation between the $\mathrm{H}$ atom donor and acceptor sites (right). For water catalysis, $d$ is taken to be the distance between its two hydrogens.

accepting oxygen of the acid and thus enhances the decomposition of $\mathrm{HHP}_{\mathrm{Cl}}$. The present results provide detailed insight into the structure-activity relationship and electronic tuning of acid catalysis in the context of gas-phase $\mathrm{H}$ atom transfer chemistry. Specifically, the optimum activity of a catalyst can be achieved by selecting an acid with two oxygen functionalities that are connected through a common center (e.g., S, N, or C) and are as far apart as possible.

3.5. $\mathrm{HHP}_{\mathrm{C} 2}$ Decomposition. We next examined the acidcatalyzed decomposition of $\mathrm{HHP}_{\mathrm{C} 2}$ to see if the structure of the HHP strongly affects its decomposition. In this case, the catalysts considered are $\mathrm{H}_{2} \mathrm{O}$ and $\mathrm{HCOOH}$. The $\Delta G^{\ddagger}$ for the uncatalyzed decompositions of cis- and trans- $\mathrm{HHP}_{\mathrm{C} 2}$ are 44.0 and $42.2 \mathrm{kcal} / \mathrm{mol}$, respectively, consistent with the prior $\operatorname{CCSD}(\mathrm{T}) / 6-311+\mathrm{G}(2 \mathrm{~d}, 2 \mathrm{p}) / / \mathrm{B} 3 \mathrm{LYP} / 6-311+\mathrm{G}(2 \mathrm{~d}, 2 \mathrm{p})$ estimate $^{20}$ of $43.9 \mathrm{kcal} / \mathrm{mol}$ for trans $-\mathrm{HHP}_{\mathrm{C} 2}$. The $\mathrm{HHP}_{\mathrm{C} 2}$ decomposition is found to have lower free-energy barriers and reaction endergonicities (for the uncatalyzed and catalyzed reactions) by $\sim 2.0-4.0 \mathrm{kcal} / \mathrm{mol}$ compared to the $\mathrm{HHP}_{\mathrm{C} 1}$ case (Figure 5; Tables 1 and S3, Supporting Information), implying that the structure of an HHP plays only a modest role in its decomposition energetics. The calculated catalytic effect of either $\mathrm{HCOOH}$ or $\mathrm{H}_{2} \mathrm{O}$ on the $\mathrm{HHP}_{\mathrm{C} 2}$ decomposition is similar to what is estimated for the $\mathrm{HHP}_{\mathrm{C} 1}$ decomposition. The presence of $\mathrm{HCOOH}$ causes a $\Delta G^{\ddagger}$ reduction of 27.8-29.2 $\mathrm{kcal} / \mathrm{mol}$, which is only $0.1-1.2 \mathrm{kcal} / \mathrm{mol}$ greater than for the $\mathrm{HHP}_{\mathrm{C} 1}$ case. The presence of $\mathrm{H}_{2} \mathrm{O}$ causes a $\Delta G^{\ddagger}$ lowering of $\sim 14.0 \mathrm{kcal} / \mathrm{mol}$ in both cases. For the alternate decomposition pathway of $\mathrm{HHP}_{\mathrm{C} 2}$ that produces acetic acid rather than acetaldehyde as the product, the calculated catalytic effect of $\mathrm{H}_{2} \mathrm{O}$ and $\mathrm{HCOOH}$ is 6.8 and $10.1-10.9 \mathrm{kcal} / \mathrm{mol} \Delta G^{\ddagger}$ lowering, respectively (Table 2 ), which is again similar to the results for the analogous $\mathrm{HHP}_{\mathrm{C} 1}$ reaction.

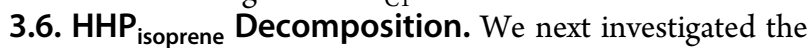
impact of conjugation by examining the $\mathrm{HHP}_{\text {isoprene }}$ decomposition reaction. We considered two conformers, $\mathrm{HHP}_{\text {isoprenel }}$

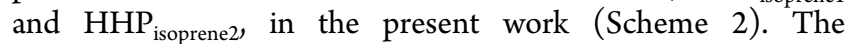
estimated free-energy barriers of 38.4-39.6 and 40.6-41.7 $\mathrm{kcal} / \mathrm{mol}$ for the uncatalyzed $\mathrm{HHP}_{\text {isoprene1 }}$ and $\mathrm{HHP}_{\text {isoprene2 }}$ decompositions (Tables 1 and S3, Supporting Information) match well with the previously reported values of 41.0 and 42.6 $\mathrm{kcal} / \mathrm{mol}$ at the G2M-RCC5//B3LYP-6-311+G(2d,2p) level of theory. ${ }^{22}$ Though the presence of a vinyl group adjacent to the

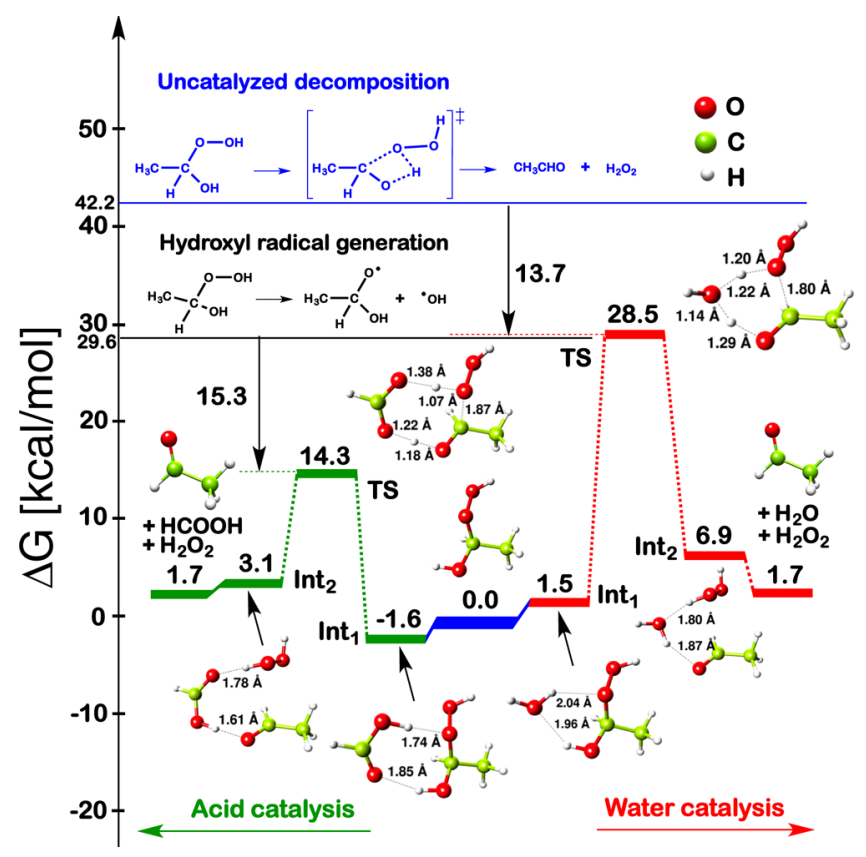

Figure 5. Same as Figure 2 but for trans- $\mathrm{HHP}_{\mathrm{C} 2}$.

hydroperoxy carbon in $\mathrm{HHP}_{\text {isoprene }}$ generally lowers the $\Delta G^{\ddagger}$, the effect is slightly more pronounced in the case of $\mathrm{HHP}_{\text {isoprene1 }}$ where the carbon-bearing hydroperoxy and hydroxyl moieties are more substituted. Moreover, the calculated barriers for the trans- $\mathrm{HHP}_{\text {isoprene }}$ decompositions are found to be $\sim 2.0 \mathrm{kcal} / \mathrm{mol}$ lower than those for the cis decompositions.

The presence of a single $\mathrm{H}_{2} \mathrm{O}$ molecule reduces the zeropoint-corrected $\Delta E^{\ddagger}$ for the cis- and trans-HHP $\mathrm{H}_{\text {isoprenel }}$ decompositions by 21.4 and $21.7 \mathrm{kcal} / \mathrm{mol}$, respectively (Figures 6 and S4, Supporting Information). However, the catalytic influence of an $\mathrm{H}_{2} \mathrm{O}$ molecule is significantly reduced upon inclusion of entropic effects, i.e., the $\Delta G^{\ddagger}$ for the cis- and trans- $\mathrm{HHP}_{\text {isoprenel }}$ decompositions are only lowered by 11.4 and $11.9 \mathrm{kcal} / \mathrm{mol}$, respectively. This agrees well with the value of $12.5 \mathrm{kcal} / \mathrm{mol}$, previously reported by Anglada et al. ${ }^{22}$ The analogous catalytic effect of a $\mathrm{H}_{2} \mathrm{O}$ molecule upon the decompositions of cis- and trans-HHP $\mathrm{H}_{\text {isoprene2 }}$ is found to be 


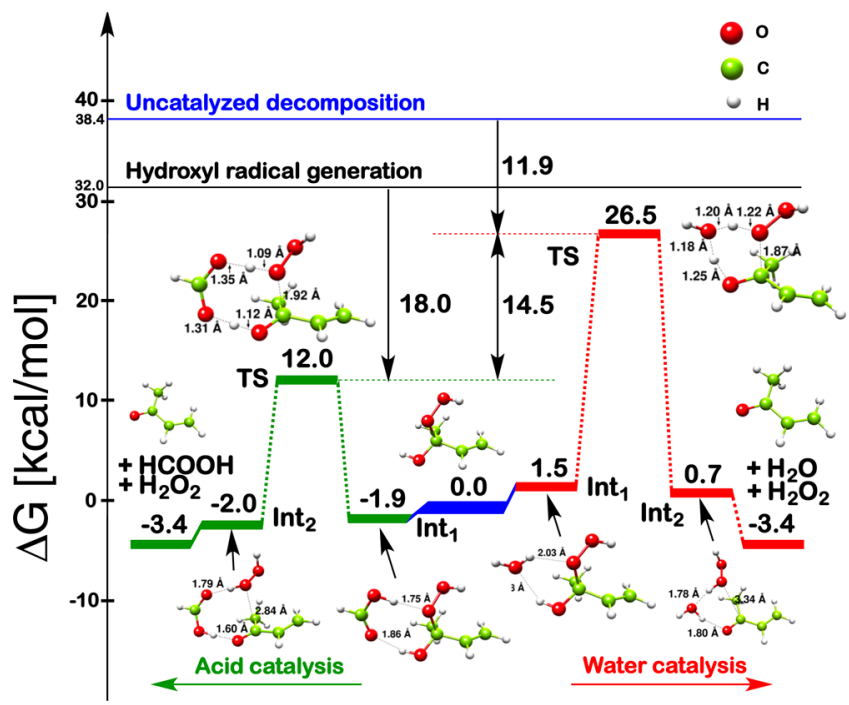

Figure 6. Same as Figure 2 but for $\mathrm{HHP}_{\text {isoprene1 }}$.

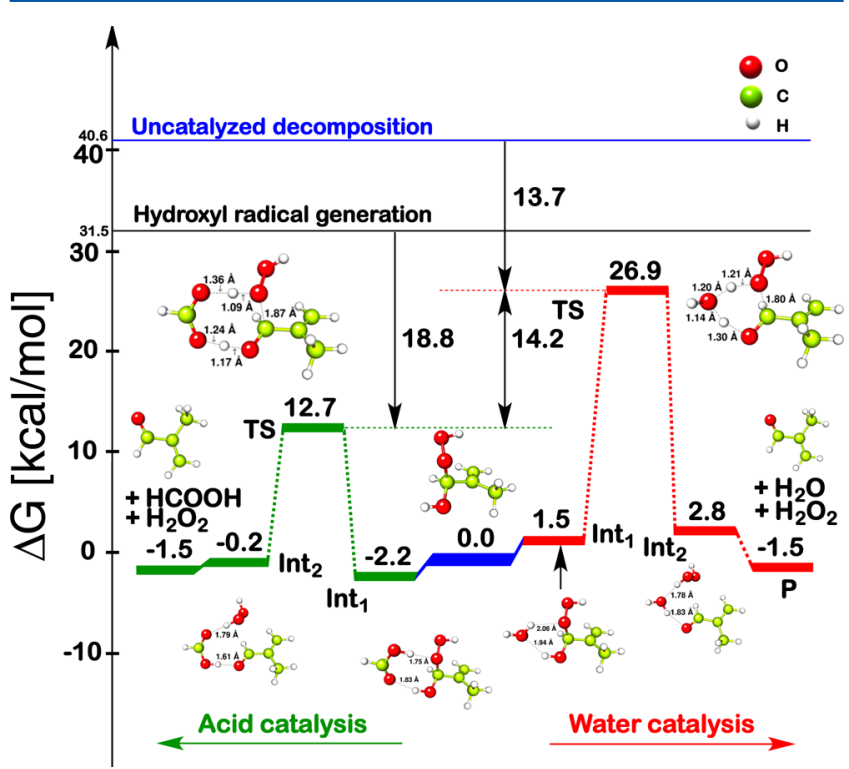

Figure 7. Same as Figure 2 but for trans- $\mathrm{HHP}_{\text {isoprene2. }}$.

13.6 and $13.7 \mathrm{kcal} / \mathrm{mol}$ (Figures 7 and S5, Supporting Information). However, for the $\mathrm{HCOOH}$-catalyzed $\mathrm{HHP}_{\text {isoprene1 }}$ and $\mathrm{HHP}_{\text {isoprene2 }}$ dissociations, a dramatic $\Delta G^{\ddagger}$ lowering of $\sim 26.0-28.0 \mathrm{kcal} / \mathrm{mol}$ is found. Moreover, the $\mathbf{I n t}_{1}$ and $\mathbf{I n t}_{2}$ involved in the $\mathrm{HCOOH}$-catalyzed decompositions of $\mathrm{HHP}_{\text {isoprene1 }}$ and $\mathrm{HHP}_{\text {isoprene2 }}$ are found to be $2.0-3.0 \mathrm{kcal} / \mathrm{mol}$ more stable than those involved in the $\mathrm{H}_{2} \mathrm{O}$-catalyzed decompositions.

3.7. Hydroxy Radical Generation via HHP Decomposition. In addition to the aldehyde- or ketone- and carboxylic acid-forming pathways, the uncatalyzed unimolecular decomposition of an HHP can lead to the formation of $\cdot \mathrm{OH}$ and hydroxyalkyl alkoxy radical via the barrierless homolytic cleavage of the perhydroxy, $\mathrm{O}-\mathrm{OH}$, linkage (Scheme 3). This mechanism has been previously explored using theoretical methods. Anglada et al. have studied the $\cdot \mathrm{OH}$ generating decomposition pathway of $\mathrm{HHP}_{\mathrm{C} 1}$ and compared its energetics to that of the $\mathrm{H}_{2} \mathrm{O}$-catalyzed reaction. ${ }^{19}$ They found that the $\cdot \mathrm{OH}$ generation reaction has $\Delta G_{\mathrm{rxn}}=27.8 \mathrm{kcal} / \mathrm{mol}, 8.9 \mathrm{kcal} /$ mol lower than the $\Delta G^{\ddagger}$ for the water-catalyzed decomposition.
Scheme 3. General Hydroxyl Radical-Producing Decomposition Pathway of an HHP

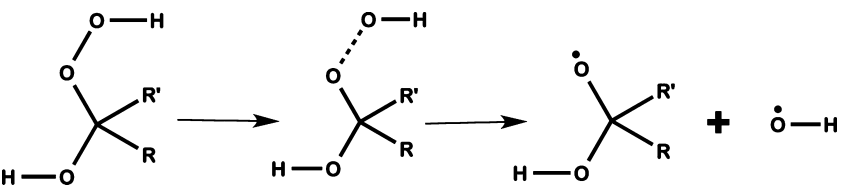

In a subsequent study, they studied the uncatalyzed and watercatalyzed decomposition of the $\mathrm{HHP}_{\mathrm{C} 2}{ }^{22}$ Again, the $\cdot \mathrm{OH}$ generation pathway $\left(\Delta G_{\mathrm{rxn}}=27.5 \mathrm{kcal} / \mathrm{mol}\right)$ was found to be favored over the water-catalyzed acetaldehyde-forming decomposition $\left(\Delta G^{\ddagger}=33.3 \mathrm{kcal} / \mathrm{mol}\right)$. They thus suggested that the HHP decomposition could be a source of tropospheric $\cdot \mathrm{OH}$. Hasson et al. have also studied the uncatalyzed decomposition of $\mathrm{HHP}_{\mathrm{C} 1}$ and $\mathrm{HHP}_{\mathrm{C} 2}$ and arrived at similar conclusions. ${ }^{23}$ However, the uncatalyzed and $\mathrm{H}_{2} \mathrm{O}$-catalyzed decomposition of isoprene-derived HHPs has been theoretically studied using several ab initio and DFT methods and was found to exclusively result in the formation of methyl vinyl ketone or methacrolein and hydrogen peroxide. ${ }^{22}$ The $\cdot \mathrm{OH}$ generating pathway, being $\sim 20.0 \mathrm{kcal} / \mathrm{mol}$ higher in reaction enthalpy than the enthalpic barrier of the $\mathrm{H}_{2} \mathrm{O}$-catalyzed reaction, was ruled out as the possible mode of decomposition. The presence of conjugation in the $\mathrm{HHP}_{\text {isoprene }}$ structure, which stabilizes the end products through resonance, accounts for the preferential formation of carbonyl compounds.

We recalculated the energetics for the $\cdot \mathrm{OH}$ generating decomposition pathway of HHPs in order to facilitate the comparison with the acid-catalyzed aldehyde or ketone-forming reaction using the same theoretical method. Note that such a homolytic $\mathrm{O}-\mathrm{OH}$ bond cleavage could involve a substantial barrier. ${ }^{62}$ However, we have not explored that possibility in the present study and have only calculated the reaction energy for the $\mathrm{O}-\mathrm{OH}$ cleavage reaction. According to our calculations, $\cdot \mathrm{OH}$ generation via $\mathrm{HHP}_{\mathrm{C} 1}$ and $\mathrm{HHP}_{\mathrm{C} 2}$ decomposition is 27.6-28.1 and 29.2-29.6 kcal/mol endergonic (Table 3),

Table 3. M06-2X/aug-cc-pVTZ-Calculated O-OH Bond Zero-Point Energy-Corrected Dissociation Energies, $\Delta E$, and Free Energies, $\Delta G$, (in $\mathrm{kcal} / \mathrm{mol}$ ) for All the HHPs Studied in This Work

\begin{tabular}{lccccc} 
& \multicolumn{3}{c}{$\mathrm{O}-\mathrm{OH}$ bond dissociation energy } \\
\cline { 2 - 3 } \cline { 5 - 6 } substrate & \multicolumn{3}{c}{$\Delta E$} & & \multicolumn{3}{c}{$\Delta G$} \\
\cline { 2 - 3 } \cline { 4 - 6 } & trans & cis & & trans & cis \\
$\mathrm{HHP}_{\mathrm{C} 1}$ & 37.6 & 37.1 & & 28.1 & 27.6 \\
$\mathrm{HHP}_{\mathrm{C} 2}$ & 39.3 & 39.0 & & 29.6 & 29.2 \\
$\mathrm{HHP}_{\text {isoprene1 }}$ & 42.1 & 40.4 & & 32.0 & 30.6 \\
$\mathrm{HHP}_{\text {isoprene2 }}$ & 41.6 & 39.9 & & 31.5 & 30.3 \\
\hline
\end{tabular}

consistent with earlier studies. ${ }^{19-23}$ However, although the $\Delta G^{\ddagger}$ for the $\mathrm{H}_{2} \mathrm{O}$-catalyzed cis- and trans- $\mathrm{HHP}_{\mathrm{C} 1}$ decompositions is 4.5 and $2.5 \mathrm{kcal} / \mathrm{mol}$ higher than the endergonicity of the $\cdot \mathrm{OH}$ generation pathway, the $\Delta G^{\ddagger}$ for the $\mathrm{HCOOH}$-catalyzed cisand trans-decompositions are 9.2 and $11.2 \mathrm{kcal} / \mathrm{mol}$ lower. This suggests that the HHP decomposition pathway is not likely to contribute to the atmospheric formation of $\cdot \mathrm{OH}$. Our findings are consistent with the studies of Neeb and Moortgat ${ }^{8}$ and Johnson et al., ${ }^{44}$ which found that the $\cdot \mathrm{OH}$ yield in olefin ozonolysis experiments is not impacted by the presence of 
$\mathrm{H}_{2} \mathrm{O}$, which is known to react with the Criegee intermediate to form HHP.

3.8. Rate Constant Estimates. The ability of an acid to significantly lower the free-energy barrier for HHP decomposition suggests that it can potentially play an important role in the formation of atmospheric $\mathrm{H}_{2} \mathrm{O}_{2}$. Therefore, we next evaluated the possible tropospheric impact of the $\mathrm{HCOOH}$ assisted $\mathrm{HHP}_{\mathrm{C} 1}, \mathrm{HHP}_{\mathrm{C} 2}, \mathrm{HHP}_{\text {isoprenel, }}$ and $\mathrm{HHP}_{\text {isoprene2 }}$ decompositions by comparing their bimolecular rate constants to those for the uncatalyzed and $\mathrm{H}_{2} \mathrm{O}$-catalyzed reactions. We have only considered trans-HHPs for kinetic analysis because their decompositions are found to be relatively faster. We have used transition state theory to calculate the rate constants for the reaction

$$
\mathrm{HHP}+\mathrm{M} \stackrel{k_{\mathrm{M}}}{\rightarrow} \mathrm{M}+\text { aldehyde or ketone }+\mathrm{H}_{2} \mathrm{O}_{2}
$$

where $\mathrm{M}$ represents the catalyst. The rate constant is then given by

$$
\begin{aligned}
& k_{\mathrm{M}}(T)=\kappa_{\mathrm{M}}(T) k_{\mathrm{M}, \mathrm{TST}}(T) \\
& k_{\mathrm{M}}(T)=\kappa_{\mathrm{M}}(T) \frac{k_{\mathrm{B}} T}{h} \frac{Q^{\ddagger}}{Q_{\mathrm{HHP}} Q_{\mathrm{M}}} \mathrm{e}^{-\Delta E^{\ddagger} / k_{\mathrm{B}} T} \\
& k_{\mathrm{M}}^{\text {eff }}(T)=k_{\mathrm{M}}(T)[\mathrm{M}]
\end{aligned}
$$

where $k_{\mathrm{B}}$ is Boltzmann's constant, $T$ is temperature, $\beta=1 / k_{\mathrm{B}} T$, $h$ is Planck's constant, $\Delta E^{\ddagger}$ is the zero point-corrected barrier height relative to the separated reactants, $[\mathrm{M}]$ is the catalyst concentration in troposphere, $k_{\mathrm{M}}^{\text {eff }}(T)$ is the effective reaction rate constant for the HHP decomposition due to the reactions with a catalyst $M$, and $Q^{\ddagger}, Q_{H H P}$, and $Q_{M}$ are the partition functions for the transition state, HHP, and catalyst, respectively, evaluated within the rigid rotor-harmonic approximation. Tunneling effects have been included based on the Boltzmann-averaged one-dimensional Eckart barrier transmission factor, $\kappa_{\mathrm{M}}(T)$. All the calculations have been performed at the M06-2X/aug-cc-pVTZ level of theory using the unscaled vibrational frequencies, and the estimated rate constants are shown in Table 4.

Table 4. M06-2X/aug-cc-pVTZ-Calculated Effective Rate Constants (in $s^{-1}$ ) for the Uncatalyzed and Water- and Formic Acid-Catalyzed Aldehyde- or Ketone-Forming GasPhase Decomposition of Various trans-HHPs Studied at $298 \mathrm{~K}$ and 1 atm

\begin{tabular}{lccc} 
& \multicolumn{3}{c}{$k_{\mathrm{M}}^{\mathrm{eff}}(\mathrm{T})$} \\
\cline { 2 - 4 } & \multicolumn{3}{c}{$\mathrm{M}$} \\
\cline { 2 - 4 } \multicolumn{1}{c}{ substrate } & none & $\mathrm{H}_{2} \mathrm{O}$ & $\mathrm{HCOOH}$ \\
trans-HHP & & & \\
trans $-\mathrm{HHP}_{\mathrm{C} 2}$ & $1.9 \times 10^{-19}$ & $1.8 \times 10^{-11}$ & $8.4 \times 10^{-9}$ \\
trans- $\mathrm{HHP}_{\text {isoprene1 }}$ & $2.5 \times 10^{-16}$ & $1.0 \times 10^{-9}$ & $6.8 \times 10^{-7}$ \\
trans- $\mathrm{HHP}_{\text {isoprene2 }}$ & $5.4 \times 10^{-15}$ & $6.9 \times 10^{-8}$ & $2.2 \times 10^{-5}$ \\
& & $1.8 \times 10^{-8}$ & $9.6 \times 10^{-6}$ \\
\hline
\end{tabular}

Since we are primarily interested in the relative effect of water and formic acid on the HHP decomposition, we calculated and compared the $k_{\mathrm{M}}^{\text {eff }}(T)$ for the HHP decomposition due to reactions with $\mathrm{H}_{2} \mathrm{O}$ and $\mathrm{HCOOH}$. Our calculations indicate that, though tunneling is significant for the uncatalyzed reactions $\left(\kappa_{\mathrm{M}} \approx 72-530\right)$, it plays a smaller role in the water or formic acid-catalyzed reactions $\left(\kappa_{\mathrm{M}}\left(\mathrm{H}_{2} \mathrm{O}\right) \approx 6.1-\right.$
22.2; $\left.\kappa_{\mathrm{M}}(\mathrm{HCOOH}) \approx 1.0-1.5\right)$. For the concentration $[\mathrm{M}]$, we have used $\left[\mathrm{H}_{2} \mathrm{O}\right] \approx 6.1 \times 10^{17}$ molecules $/ \mathrm{cm}^{3}$ and $[\mathrm{HCOOH}]$ $\approx 5 \times 10^{10}$ molecules $/ \mathrm{cm}^{3}$. These values have been taken from a recent study by Vereecken et al., ${ }^{16}$ in which they have summarized concentrations of various species in different environments based on previous literature estimates.

Using these data, the estimated effective rate constant for the water-catalyzed decomposition of trans-HHP $\mathrm{C}_{1}$ is then $k_{\mathrm{H}_{2} \mathrm{O}}^{\text {eff }}(T)$ $=1.8 \times 10^{-11} \mathrm{~s}^{-1}$, representing an enhancement in the decomposition rate constant by a factor of $2.3 \times 10^{7}$ as compared to the uncatalyzed decomposition $(k(T)=7.9 \times$ $\left.10^{-19} \mathrm{~s}^{-1}\right)$. For the formic acid-catalyzed trans-HHP $\mathrm{C}_{\mathrm{C} 1}$ decomposition, $k_{\mathrm{HCOOH}}^{\text {eff }}(T)=8.4 \times 10^{-9} \mathrm{~s}^{-1}$, an increase of a factor of $\sim 10^{10}$ over the uncatalyzed reaction, and more importantly, $\sim 10^{2}$ over the water-catalyzed reaction. The calculated effective reaction rate constants for the uncatalyzed and water- and formic acid-catalyzed trans-HHP $\mathrm{C}_{\mathrm{C} 2}$ decomposition also imply that the formic acid-catalyzed reaction is faster than a water-catalyzed reaction (Table 4). Interestingly, the unimolecular rate constant for the $\mathrm{H}_{2} \mathrm{O}$-catalyzed decomposition of $\mathrm{HHP}_{\text {isoprene2 }}$ has been previously reported using classical TST, wherein the B3LYP/6-31G(d,p)-calculated partition functions and G2M-RRC5-calculated energies were used. ${ }^{22}$ Our calculated value of $1.5 \times 10^{-6} \mathrm{~s}^{-1}$ is in reasonable agreement with this prior estimate of $1.0 \times 10^{-7} \mathrm{~s}^{-1}$. Similar rate constant estimates for the $\mathrm{HHP}_{\text {isoprenel }}$ decomposition predict that the formic acid-catalyzed reaction is $\sim 10^{3}$ faster than the water-catalyzed one, which represents an order of magnitude additional enhancement compared to the other formic acid-catalyzed decompositions studied here. Overall, these results suggest that organic acids in the troposphere should play a larger role than water in HHP decomposition. Recent satellite measurements over boreal and tropical forests, ${ }^{63}$ which indicate that the actual atmospheric $\mathrm{HCOOH}$ levels are two to three times higher than those that have been commonly perceived, further support such a possibility. The catalytic effect of incorporating organic acids into sulfuric acid aerosol models has been verified through laboratory experiments. $^{64}$

\section{CONCLUSIONS}

In this article, a computational investigation of the unimolecular, $\mathrm{H}_{2} \mathrm{O}$-catalyzed, and acid-catalyzed decomposition of the $\alpha$-hydroxyalkyl hydroperoxides $\mathrm{HHP}_{\mathrm{C} 1}, \mathrm{HHP}_{\mathrm{C} 2}$, $\mathrm{HHP}_{\text {isoprene1, }}$ and $\mathrm{HHP}_{\text {isoprene2 }}$ has been reported. The unimolecular decomposition of HHPs involves high freeenergy barriers $\left(\Delta G^{\ddagger} \approx 39-59 \mathrm{kcal} / \mathrm{mol}\right)$; the pathway yielding an aldehyde or ketone and $\mathrm{H}_{2} \mathrm{O}_{2}$ is favored over that leading to a carboxylic acid and $\mathrm{H}_{2} \mathrm{O}$. Because of its lower free-energy barrier, the former pathway is expected to play an important role in the tropospheric decomposition of HHPs.

In the atmosphere, these HHPs can react with an $\mathrm{H}_{2} \mathrm{O}$ molecule, which acts as a catalyst, to produce the same products as those found for the unimolecular decomposition. The presence of $\mathrm{H}_{2} \mathrm{O}$ causes an appreciable lowering of $\sim 8.0$ and $14.0 \mathrm{kcal} / \mathrm{mol}$ in the free-energy barrier for the carboxylic acidforming and aldehyde- or ketone-forming decomposition pathways, respectively. For $\mathrm{HHP}_{\mathrm{C} 1}$ decomposition, the freeenergy barrier for $\mathrm{H}_{2} \mathrm{O}$-catalyzed formaldehyde-forming pathway is, however, $2.5-4.5 \mathrm{kcal} / \mathrm{mol}$ higher than the reaction free energy for forming $\cdot \mathrm{OH}$ and hydroxymethyl methoxy radicals, whereas for $\mathrm{HHP}_{\mathrm{C} 2}$ decomposition these two pathways, 
because of their similar energetics, are both possible. Because of this, earlier theoretical studies ${ }^{33,36}$ suggested that decomposition of these simpler HHPs could be a source of tropospheric $\cdot \mathrm{OH}$. However, the free-energy barrier for the $\mathrm{H}_{2} \mathrm{O}$-catalyzed methyl vinyl ketone- or methacrolein-forming decomposition pathway of $\mathrm{HHP}_{\text {isoprene1 }}$ or $\mathrm{HHP}_{\text {isoprene2 }}$ is $\sim 4.6-5.5 \mathrm{kcal} / \mathrm{mol}$ lower than the reaction free energy for the $\cdot \mathrm{OH}$ generating pathway, implying that this decomposition should produce a carbonyl compound and $\mathrm{H}_{2} \mathrm{O}_{2}$ under atmospheric conditions.

The present DFT calculations on the acid-catalyzed decomposition of HHPs indicate that the effect of an acid molecule on the free-energy barrier for the aldehyde- or ketoneforming pathway is dramatically greater than that of a water molecule. The free-energy barrier for an acid-catalyzed reaction is $\sim 13-15 \mathrm{kcal} / \mathrm{mol}$ lower than that for the water-catalyzed one, suggesting that acid catalysis might offer a more favorable mechanism for HHP decomposition than that involving water catalysis. Although the $\mathrm{H}_{2} \mathrm{O}$ concentration in the lower atmosphere is $\sim 5$ orders of magnitude higher than that of organic acids, the estimated effective rate constants for formic acid-catalyzed reactions are $\sim 2-3$ orders of magnitude higher than those for the water-catalyzed reactions, favoring an acidcatalyzed reaction. This new mechanism should not only improve our understanding of atmospheric $\mathrm{H}_{2} \mathrm{O}_{2}$ formation, but provides insight into potential routes for producing industrially relevant carbonyl compounds.

The calculations reveal that the catalytic effect of an acid directly correlates with the distance between the H-donor and $\mathrm{H}$-acceptor sites and can be further tuned by making judicious substitutions at its carbonyl carbon. Since the free-energy barrier for the acid-catalyzed decomposition is significantly lower (by $>10 \mathrm{kcal} / \mathrm{mol}$ ) than the free energy required for cleaving the $\mathrm{O}-\mathrm{OH}$ bond of the $\mathrm{HHP}$ to form $\cdot \mathrm{OH}$, the calculations suggest that HHP decomposition may not be an important source of atmospheric $\cdot \mathrm{OH}$. The present results not only furnish important mechanistic information about the nonphotochemical source of gas-phase $\mathrm{H}_{2} \mathrm{O}_{2}$ but also provide valuable guidelines for designing novel catalysts for promoting other industrially and environmentally important $\mathrm{H}$ atom transfer reactions such as dehydration of alcohols and dehydrohalogenation of halogenated hydrocarbons.

\section{ASSOCIATED CONTENT}

\section{S Supporting Information}

Calculated reaction profiles and thermodynamic data. This material is available free of charge via the Internet at http:// pubs.acs.org.

\section{AUTHOR INFORMATION}

\section{Corresponding Author}

*E-mail: wthompson@ku.edu.

\section{Notes}

The authors declare no competing financial interest.

\section{ACKNOWLEDGMENTS}

We thank Dr. Michael Lundin and Dr. Andrew Danby for many useful discussions. This work is funded by NIFA/USDA grant no. 2011-10006-30362.

\section{REFERENCES}

(1) Kroll, J. H.; Clarke, J. S.; Donahue, N. M.; Anderson, J. G.; Demerjian, K. L. Mechanism of HOx formation in the gas-phase ozone-alkene reaction: 1 . Direct pressure-dependent measurements of $\mathrm{OH}$ yields. J. Phys. Chem. A 2001, 105, 1554-1560.

(2) Kroll, J. H.; Shahai, S.; Anderson, J. G.; Demerjian, K. L.; Donahue, N. M. Mechanism of HOx formation in the gas-phase ozone-alkene reaction: 2. Prompt versus thermal dissociation of carbonyl oxides to form OH. J. Phys. Chem. A 2001, 105, 4446-4457.

(3) Kroll, J. H.; Cee, V. J.; Donahue, N. M.; Demerjian, K. L.; Anderson, J. G. Gas-phase ozonolysis of alkenes: formation of $\mathrm{OH}$ from anti carbonyl oxides. J. Am. Chem. Soc. 2002, 124, 8518-8519.

(4) Becker, K. H.; Brockmann, K. J.; Bechara, J. Production of hydrogen peroxide in forest air by reaction of ozone with terpenes. Nature 1990, 346, 256-268.

(5) Becker, K. H.; Bechara, J.; Brockmann, K. J. Studies on the formation of $\mathrm{H}_{2} \mathrm{O}_{2}$ in the ozonolysis of alkenes. Atmos. Environ. 1993, 27A, 57-61.

(6) Sauer, F.; Schäfer, C.; Neeb, P.; Horie, O.; Moortgat, G. K. Formation of hydrogen peroxide in the ozonolysis of isoprene and simple alkenes under humid conditions. Atmos. Environ. 1999, 33, 229-241.

(7) Niki, H.; Maker, P. D.; Savage, C. M.; Breitenbach, L. P.; Hurley, M. D. FTIR spectroscopic study of the mechanism for the gas-phase reaction between ozone and tetramethylethylene. J. Phys. Chem. 1987, 91, 941-946.

(8) Neeb, P.; Moortgat, G. K. Formation of $\mathrm{OH}$ radicals in the gasphase reaction of propene, isobutene and isopropene with $\mathrm{O}_{3}$. Yields and mechanistic implications. J. Phys. Chem. A 1999, 103, 9003-9015.

(9) Zhang, D.; Zhang, R. Mechanism of $\mathrm{OH}$ formation from ozonolysis of isoprene: A quantum-chemical study. J. Am. Chem. Soc. 2002, 124, 2692-2703.

(10) Fenske, J. D.; Kuwata, K. T.; Houk, K. N.; Paulson, S. E. OH radical yields from the ozone reaction with cycloalkenes. J. Phys. Chem. A 2000, 104, 7246-7254.

(11) Fenske, J. D.; Hasson, A. S.; Paulson, S. E.; Kuwata, K. T.; Ho, A.; Houk, K. N. The pressure dependence of the $\mathrm{OH}$ radical yield from ozone-alkene reactions. J. Phys. Chem. A 2000, 104, 7821-7833.

(12) Horie, O.; Moortgat, G. K. Decomposition pathways of the excited Criegee intermediates in the ozonolysis of simple alkenes. Atmos. Environ. 1991, 25A, 1881-1896.

(13) Atkinson, R. Gas-phase tropospheric chemistry of volatile organic compounds: 1. Alkanes and alkenes. J. Phys. Chem. Ref. Data 1997, 26, 215-290.

(14) Horie, O.; Moortgat, G. K. Gas-phase ozonolysis of alkenes. Recent advances in mechanistic investigations. Acc. Chem. Res. 1998, 31, 387-396.

(15) Vereecken, L.; Harder, H.; Novelli, A. The reaction of Criegee intermediates with $\mathrm{NO}, \mathrm{RO}_{2}$ and $\mathrm{SO}_{2}$, and their fate in the atmosphere. Phys. Chem. Chem. Phys. 2012, 14, 14682-14695.

(16) Vereecken, L.; Harder, H.; Novelli, A. The reactions of Criegee intermediates with alkenes, ozone, and carbonyl oxides. Phys. Chem. Chem. Phys. 2014, 16, 4039-4049.

(17) Kjaergaard, H. G.; Kurtén, T.; Nielsen, L. B.; Jørgensen, S.; Wennberg, P. O. Criegee intermediate reacts with ozone. J. Phys. Chem. Lett. 2013, 4, 2525-2529.

(18) Anglada, J. M.; Gonzalez, J.; Torrent-Sucarrat, M. Effects of the substituents on the reactivity of carbonyl oxides. A theoretical study on the reaction of substituted carbonyl oxides with water. Phys. Chem. Chem. Phys. 2011, 13, 13034-13045.

(19) Crehuet, R.; Anglada, J. M.; Bofill, J. M. Tropospheric formation of hydroxymethyl hydroperoxide, formic acid, $\mathrm{H}_{2} \mathrm{O}_{2}$, and $\mathrm{OH}$ from carbonyl oxide in the presence of water vapor: A theoretical study of the reaction mechanism. Chem.-Eur. J. 2001, 7, 2227-2235.

(20) Anglada, J. M.; Aplincourt, P.; Bofill, J. M.; Cremer, D. Atmospheric formation of $\mathrm{OH}$ radicals and $\mathrm{H}_{2} \mathrm{O}_{2}$ from alkene ozonolysis under humid conditions. ChemPhysChem 2002, 2, 215221.

(21) Aplincourt, P.; Anglada, J. M. Theoretical studies on isoprene ozonolysis under tropospheric conditions. 1. Reaction of substituted carbonyl oxides with water. J. Phys. Chem. A 2003, 107, 5798-5811. 
(22) Aplincourt, P.; Anglada, J. M. Theoretical studies of the isoprene ozonolysis under tropospheric conditions. 2. Unimolecular and waterassisted decomposition of the $\alpha$-hydroxy hydroperoxides. J. Phys. Chem. A 2003, 107, 5812-5820.

(23) Hasson, A. S.; Chung, M. Y.; Kuwata, K. T.; Converse, A. D.; Krohn, D.; Paulson, S. E. Reaction of Criegee intermediates with water vapors: An additional source of $\mathrm{OH}$ radicals in alkene ozonolysis? J. Phys. Chem. A 2003, 107, 6176-6182.

(24) Kuwata, K. T.; Templeton, K. L.; Hasson, A. S. Computational studies of the chemistry of syn-acetaldehyde oxide. J. Phys. Chem. A 2003, 107, 11525-11532.

(25) Kuwata, K. T.; Hermes, M. R.; Carlson, M. J.; Zogg, C. K. Computational studies of the isomerization and hydration reactions of acetaldehyde oxide and methyl vinyl carbonyl oxide. J. Phys. Chem. A 2010, 114, 9192-9204.

(26) Welz, O.; Savee, J. D.; Osborn, D. L.; Vasu, S. S.; Percival, C. J.; Shallcross, D. E.; Taatjes, C. A. Direct kinetic measurements of Criegee intermediate $\left(\mathrm{CH}_{2} \mathrm{OO}\right)$ formed by reaction of $\mathrm{CH}_{2} \mathrm{I}$ with $\mathrm{O}_{2}$. Science 2012, 335, 204-207.

(27) Taatjes, C. A.; Welz, O.; Eskola, A. J.; Savee, J. D.; Scheer, A. D.; Shallcross, D. E.; Rotavera, B.; Lee, E. P. F.; Dyke, J. M.; Mok, D. K. W.; et al. Direct measurements of conformer-dependent reactivity of the Criegee intermediate $\mathrm{CH}_{3} \mathrm{CHOO}$. Science 2013, 340, 177-180.

(28) Welz, O.; Eskola, A. J.; Sheps, L.; Rotavera, B.; Savee, J. D.; Scheer, A. M.; Osborn, D. L.; Lowe, D.; Booth, A. M.; Xiao, P.; et al. Rate coefficients of $\mathrm{C} 1$ and $\mathrm{C} 2$ Criegee intermediate reactions with formic and acetic acid near the collision limit: direct kinetics measurements and atmospheric implications. Angew. Chem., Int. Ed. 2014, 53, 1-5.

(29) Johnson, D.; Marston, G. The gas-phase ozonolysis of unsaturated volatile organic compounds in the troposphere. Chem. Soc. Rev. 2008, 37, 699-716.

(30) Becker, K. H.; Barnes, I.; Ruppert, L.; Wiesen, P. In Free Radicals in Biology and Environment; Minisci, F., Ed.; Kluwer: Dordrecht, The Netherlands, 1996; p 365.

(31) Gäb, S.; Hellpointner, E.; Turner, W. V.; Korte, F. Hydroxymethyl hydroperoxide and bis(hydroxymethyl) peroxide from gas-phase ozonolysis of naturally occurring alkenes. Nature 1985, 316, 535-536.

(32) Neeb, P.; Sauer, F.; Horie, O.; Moortgat, G. K. Formation of hydroxymethyl hydroperoxide and formic acid in alkene ozonolysis in the presence of water vapor. Atmos. Environ. 1997, 31, 1417-1423.

(33) Wolff, S.; Boddenberg, A.; Thamm, J.; Turner, W. V.; Gäb, S. Gas phase ozonolysis of ethene in the presence of carbonyl oxide scavengers. Atmos. Environ. 1997, 31, 2965-2969.

(34) Tanner, R. L.; Schorran, D. E. Measurements of gaseous peroxides near the Grand Canyon: Implication for summertime visibility impairment from aqueous-phase secondary sulfate formation. Atmos. Environ. 1995, 29, 1113-1122.

(35) Husain, L.; Rattigan, O. V.; Dutkiewicz, V.; Das, M.; Judd, C. D.; Khan, A. R.; Richter, R; Balasubramanian, R.; Swami, K.; Walcek, C. J. Case studies of the $\mathrm{SO}_{2}+\mathrm{H}_{2} \mathrm{O}_{2}$ reaction in clouds. J. Geophys. Res. 2000, 105, 9331-9341.

(36) Rattigan, O. V.; Boniface, J.; Swartz, E.; Davidovits, P.; Jayne, J. T.; Kolb, C. E.; Worsnop, D. R. Uptake of gas-phase $\mathrm{SO}_{2}$ in aqueous sulfuric acid: Oxidation by $\mathrm{H}_{2} \mathrm{O}_{2}, \mathrm{O}_{3}$, and HONO. J. Geophys. Res. 2000, 105, 29065-29078.

(37) Lelieveld, J.; Heintzenberg, J. Sulfate cooling effect on climate through in-cloud oxidation of anthropogenic $\mathrm{SO}_{2}$. Science 1992, 258, $117-120$.

(38) Clancy, R. T.; Sandor, B. J.; Moriarty-Schiven, G. H. A measurement of the $362 \mathrm{GHz}$ absorption line of Mars atmospheric $\mathrm{H}_{2} \mathrm{O}_{2}$. Icarus 2004, 168, 116-121.

(39) Thompson, A. M. The oxidizing capacity of the earth's atmosphere: Probable past and future changes. Science 1992, 256, $1157-1165$.

(40) Calvert, J. G.; Stockwell, W. R. Acid generation in the troposphere by gas-phase chemistry. Environ. Sci. Technol. 1983, 17, 428A-443A.
(41) Kleinman, L. I. Photochemical formation of peroxides in the boundary layer. J. Geophys. Res. 1986, 91, 10889-10904.

(42) Jenkin, M. E.; Saunders, S. M.; Pilling, M. J. The tropospheric degradation of volatile organic compounds: A protocol for mechanism development. Atmos. Environ. 1997, 31, 81-104.

(43) Rebrovic, L. The peroxidic species generated by ozonolysis of oleic acid or methyl oleate in a carboxylic acid medium. J. Am. Oil Chem. Soc. 1992, 69, 159-165.

(44) Johnson, D.; Lewin, A. G.; Marston, G. The effect of Criegeeintermediate scavengers on the $\mathrm{OH}$ yield from the reaction of ozone with 2-methylbut-2-ene. J. Phys. Chem. A 2001, 105, 2933-2935.

(45) Winterhalter, R.; Neeb, P.; Grossmann, D.; Kolloff, A.; Horie, O.; Moortgat, G. K. Products and mechanism of the gas phase reaction of ozone with beta-pinene. J. Atmos. Chem. 2000, 35, 165-197.

(46) Hasson, A. S.; Ho, A. W.; Kuwata, K. T. Production of stabilized Criegee intermediates and peroxides in the gas phase ozonolysis of alkenes: 2. Asymmetric and biogenic alkenes. J. Geophys. Res. 2001, 106, 34143-34153.

(47) Granby, K.; Christensen, C. S.; Lohse, C. Urban and semi-rural observations of carboxylic acids and carbonyls. Atmos. Environ. 1997, $31,1403-1415$

(48) Chebbi, A.; Carlier, P. Carboxylic acids in the troposphere, occurrence, sources, and sinks: A review. Atmos. Environ. 1996, 30, $4233-4249$.

(49) Kumar, M.; Busch, D. H.; Subramaniam, B.; Thompson, W. H. Organic acids tunably catalyze carbonic acid decomposition. J. Phys. Chem. A 2014, 118, 1887-1894.

(50) da Silva, G. Carboxylic acid catalyzed keto-enol tautomerizations in the gas phase. Angew. Chem., Int. Ed. 2010, 49, 7523-7525.

(51) Buszek, R. J.; Sinha, A.; Francisco, J. S. The isomerization of methoxy radical: Intramolecular hydrogen atom transfer mediated through acid catalysis. J. Am. Chem. Soc. 2011, 133, 2013-2015.

(52) Hazra, M. K.; Sinha, A. Formic acid catalyzed hydrolysis of $\mathrm{SO}_{3}$ in the gas phase: A barrierless mechanism for sulfuric acid production of potential atmospheric importance. J. Am. Chem. Soc. 2011, 133, 17444-17453.

(53) Jalan, A.; Alecu, I. M.; Meana-Paneda, R.; Aguilera-Iparraguirre, J.; Yang, K. R.; Merchant, S. S.; Truhlar, D. G.; Green, W. H. New pathways for formation of acids and carbonyl products in lowtemperature oxidation: The Korcek decomposition of $\gamma$-ketohydroperoxides. J. Am. Chem. Soc. 2013, 135, 11100-11114.

(54) Maeda, S.; Komagawa, S.; Uchiyama, M.; Morokuma, K. Finding reaction pathways for multicomponent reactions: The Passerini reaction is a four-component reaction. Angew. Chem., Int. Ed. 2011, 50, 644-649.

(55) Warnecke, C.; Holzinger, R.; Hansel, A.; Jordan, A.; Lindinger, W.; Poschl, U.; Williams, J.; Hoor, P.; Fischer, H.; Crutzen, P. J.; et al. Isoprene and its oxidation products methyl vinyl ketone, methacrolein, and isoprene related peroxides measured online over the tropical rain forest of Surinam in March 1998. J. Atmos. Chem. 2001, 38, 167-185.

(56) Neese, F.; Wennmohs, N.; Hansen, A. Efficient and accurate local approximations to coupled-electron pair approaches: An attempt to revive the pair natural orbital method. J. Chem. Phys. 2009, 130, 114108 .

(57) Antony, J.; Grimme, S.; Liakos, D. G.; Neese, F. Protein-ligand interaction energies with dispersion corrected density functional theory and high-level wave function based methods. J. Phys. Chem. A 2011, 115, 11210-11220.

(58) Albert, A.; Serjeant, E. P. Ionization Constants of Acids and Bases; Meuthen: London, U.K., 1962.

(59) Valiev, M.; Bylaska, E. J.; Govind, N.; Kowalski, K.; Straatsma, K. P.; van Dam, H. J. J.; Wang, D.; Nieplocha, J.; Apra, E.; Windus, T. L.; de Jong, W. A. NWChem: A comprehensive and scalable opensource solution for large scale molecular simulations. Comput. Phys. Commun. 2010, 181, 1477-1489.

(60) Neese, F. ORCA V2.8.0, an ab initio, DFT, and semiempirical SCF-MO package; Bonn University: Bonn Germany; available online from http://cec.mpg.de/forum/. 
(61) Sardon, H.; Engler, A. C.; Chan, J. M. W.; García, J. M.; Coady, D. J.; Pascual, A.; Mecerreyes, D.; Jones, G. O.; Rice, J. E.; Horn, H. W.; et al. Organic acid-catalyzed polyurethane formation via a dualactivated mechanism: unexpected preference of $\mathrm{N}$-activation over $\mathrm{O}$ activation of isocyanates. J. Am. Chem. Soc. 2013, 135, 16235-16241.

(62) Kurtén, T.; Donahue, N. M. MRCISD studies of the dissociation of vinylhydroperoxide, $\mathrm{CH}_{2} \mathrm{CHOOH}$ : There is a saddle point. J. Phys. Chem. A 2012, 116, 6823-6830.

(63) Stavrakou, T.; Müller, J.-F.; Peeters, J.; Razavi, A.; Clarisse, L.; Clerbaux, C.; Coheur, P.-F.; Hurtmans, D.; De Mazière, M.; Vigouroux, C.; et al. Satellite evidence for a large source of formic acid from boreal and tropical forests. Nat. Geosci. 2012, 5, 26-30.

(64) Zhang, R.; Suh, I.; Zhao, J.; Zhang, D.; Fortner, E. C.; Tie, X.; Molina, L. T.; Molina, M. J. Atmospheric new particle formation enhanced by organic acids. Science 2004, 304, 1487-1490. 